\title{
First-Principles-Based Kinetic Monte Carlo Simulation of Nitric Oxide Reduction over Platinum Nanoparticles under Lean-Burn Conditions
}

\author{
Donghai Mei, ${ }^{\dagger, \ddagger}$ Jincheng Du, ${ }^{\dagger}$ and Matthew Neurock $*, \dagger, \S$ \\ Department of Chemical Engineering, University of Virginia, Charlottesville, Virginia 22904, Institute for \\ Interfacial Catalysis, Pacific Northwest National Laboratory, Richland, Washington 99352, and Department of \\ Chemistry, University of Virginia, Charlottesville, Virginia 22904
}

\begin{abstract}
The kinetics for NO reduction over supported platinum under lean condition were investigated by firstprinciples-based kinetic Monte Carlo simulation over three-dimensional Pt nanoparticles. Model platinum nanoparticles with diameters ranging from 2.3 to $4.6 \mathrm{~nm}$ were constructed using a truncated octahedral cluster consisting of a two (100) facets and eight (111) facets. First-principles density functional theory (DFT) calculations were used to calculate the intrinsic kinetic parameters including the binding energies for all of the surface intermediates as well as the activation barriers and reaction energies that comprise the reaction mechanism over the (100) and (111) facets, as well as the (111)/(100) edge sites on the three-dimensional nanoparticle. Both intra- and inter-facet diffusion of adsorbates were included to model surface diffusion effects over the particle surface. The simulation results show that under lean conditions where there is excess oxygen, $\mathrm{NO}$ reduction to $\mathrm{N}_{2}$ occurs solely on the (100) facets. The oxidation of $\mathrm{NO}$ to $\mathrm{NO}_{2}$, while much more favored on the (111) facets, can occur on both (100) and (111) facets. Only small amounts of $\mathrm{N}_{2} \mathrm{O}$ form over the (100) facets. The simulated apparent activation energies for $\mathrm{N}_{2}$ and $\mathrm{NO}_{2}$ formation over the entire particle are 45 and $42 \mathrm{~kJ} / \mathrm{mol}$, respectively. The latter is in agreement with experimentally measured value of $39 \mathrm{~kJ} / \mathrm{mol}$ [Mulla, S. S., et al., Catal. Lett. 2005, 100, 267]. The effects of particle size on the activities of $\mathrm{NO}$ reduction to $\mathrm{N}_{2}$ and $\mathrm{NO}$ oxidation to $\mathrm{NO}_{2}$ depend upon the ratios of exposed surface sites. For the threedimensional model Pt nanoparticles examined here, the fractions of the (100) terrace sites are similar while the fraction of the (111) terrace sites increases with increasing particle size. As a result, the activity for NO reduction is somewhat insensitive to the particle size which symmetrically increases the numbers of (111) and (100) facets as the size increases. NO reduction, however, increases much more dramatically when the number of the (100) sites increases over the (111) sites. NO oxidation activity, on the other hand, appears to increase with increasing particle size regardless of the symmetry or shape of the particle as the reaction occurs predominantly over the (111) sites but can also take place on the (100) terrace sites. The structure insensitivity for $\mathrm{NO}$ oxidation is consistent with experimental results.
\end{abstract}

\section{Introduction}

NO decomposition and oxidation over supported Pt catalysts are critical steps in the three predominant $\mathrm{NO}_{x}$ abatement strategies: direct decomposition, selective catalytic reduction, and $\mathrm{NO}_{x}$ storage and reduction. While there have been a number of important studies on the factors that control NO reduction and oxidation, ${ }^{1-4}$ there are still a number of unanswered questions concerning the mechanisms by which these reactions proceed and the influence of Pt particle size and structure.

Both oxidation and reduction are known to be structuresensitive reactions demonstrating enhanced catalytic activity as the catalyst particle size is increased..$^{1-4}$ These changes with particle size have been attributed to changes in the particle shape, ${ }^{5}$ metal support effects, ${ }^{4}$ particle sintering, ${ }^{6}$ and oxide formation. ${ }^{7}$ In general, increasing the particle size leads to distinct structural and morphological changes that can subsequently influence the overall catalytic behavior. Larger particles tend to be more stable and take on more well-defined closedpacked structural forms that lead to the formation of icosohedral or cuboctahedral morphologies that are composed of stable (111) surfaces that can readily catalyze NO oxidation. Particles that

* To whom correspondence should be addressed. E-mail: mn4n@ virginia.edu.

Department of Chemical Engineering, University of Virginia.

$\doteqdot$ Pacific Northwest National Laboratory.

$\S$ Department of Chemistry, University of Virginia. are on the order of $3 \mathrm{~nm}$ or less have too few closed-packed terraces and as such are less active. These smaller particles are composed of much higher fractions of edge, corner, and other defect sites, which are coordinatively unsaturated. These sites tend to bind with the intermediates such as atomic oxygen and NO too strongly and thus become readily inhibited. These sites are also more prone than the terraces to dissolution, poisoning, and inhibition.

Herein we examine some of the mechanistic features that control particle size effects and examine their influence on the direct $\mathrm{NO}_{x}$ decomposition. While one can prepare well-defined model supported particles, the determination of site-resolved kinetics information under reaction conditions is still difficult to obtain. ${ }^{8}$ Theory and simulation can be used to complement such experimental efforts. Kinetic Monte Carlo simulations, for example, can be used to explicitly track individual molecular transformations over specific sites and thus provide a detailed analysis of structure sensitivity as well as particle size effects. Zhdanov and Kasemo, for example, recently simulated CO oxidation over supported Pt and Pd nanoparticles ${ }^{9,10}$ as well as other catalytic systems ${ }^{11,12}$ using kinetic Monte Carlo simulation within the framework of a simple lattice-gas model together with a two-dimensional model to distinguish the (100) and the (111) facets of truncated pyramidal particles. These simulations provide a wealth of information on site specificity but require a rather comprehensive database of elementary kinetic parameters that are difficult to extract from experiment. 
First-principles density functional theory (DFT) calculations have been widely used to elucidate the nature of surface intermediates and plausible reaction paths over various different transition metals, alloys, and metal oxide surfaces and can thus begin to provide necessary kinetics for KMC simulations. ${ }^{13}$ Previously we discussed DFT results which reported the adsorption energies of $\mathrm{NO}, \mathrm{O}$, and $\mathrm{N}$ as well as $\mathrm{NO}$ dissociation barriers on three Pt structure surfaces, i.e., $\mathrm{Pt}(100), \operatorname{Pt}(211)$, and $\operatorname{Pt}(410) .{ }^{14}$ Different paths for the dissociation of NO were examined over these surfaces in detail. The (100) facets were found to be essential for breaking the NO bond. The squarely arranged platinum atoms are optimal since they provide two separate bridge sites that can accept the nitrogen and oxygen atoms that form in the transition state thus avoiding the sharing of metal atoms. This significantly decreases the repulsion in the transition state leading to a much lower activation barrier. Open surfaces were also found to be more active. The reactivity order for NO dissociation was calculated to be $\operatorname{Pt}(410)>\operatorname{Pt}(211)$ $>\mathrm{Pt}(100)$. The DFT calculated barriers for NO dissociation were calculated to be in good agreement with the experimental results of Masel. ${ }^{5}$ All of our previous theoretical results were used to help construct the kinetic database needed for the kinetic Monte Carlo simulations.

Herein, we carry out first-principles-based kinetic Monte Carlo simulations over three-dimensional Pt particles to examine the influence of particle size effects on NO decomposition and oxidation. We specifically examine only the structural effects that take place as the size of the particle is increased. We do not explicitly include the influence of oxidation state, sintering, or support effects. As such, we can solely examine the effects of particle size. The approach used herein extends our previous studies of NO decomposition over $\mathrm{Pt}(100), \mathrm{Rh}(100)$, and $\mathrm{Pt}-\mathrm{Au}(100)$ surfaces $^{15,16}$ from two-dimensions to three-dimensions, and thus allows us to simulate more realistic catalytic particles at experimental conditions.

\section{Simulation Method}

2.1. Model Nanoparticle. The most stable particle morphologies that can form on a support depend upon the size and composition of the metal clusters that form, their interactions with the support, and the methods by which they are synthesized. The morphology that results dictates the relative ratio of different surface facets and sites that are exposed. The equilibrium shape of a free metal particle (without support) can, in general, be predicted, or at least understood, by the Wulff rules of construction that involve minimizing the surface energies of the exposed facets of the particle. The lowest free energy structure for a Pt nanoparticle, as well as for most fcc metals, is cuboctahedral which consists of (111) and (100) facets. The (111) facets tend to dominate the surface of the particle. ${ }^{17}$ The nanoparticle shape, however, can change under reaction conditions or after high-temperature pretreatment as the result of reconstruction or sintering. It has been found, for example, that the Pt particle shape changes from a cuboctahedral in the reducing reaction environment to a more spherical shape in an oxidizing environment. ${ }^{17}$

Herein we use the truncated octahedral structure shown in Figure 1 which is composed of eight (111) facets and two (100) facets as a model of the Pt nanoparticles. It maintains most of the same structural features found in the low-energy cuboctahedral form in that the surface is composed of (100) and (111) facets, the (111) facets dominate, and the particle is nearly spherical in form. In addition, the truncated octahedral structure was much easier to program. We model the chemistry over the

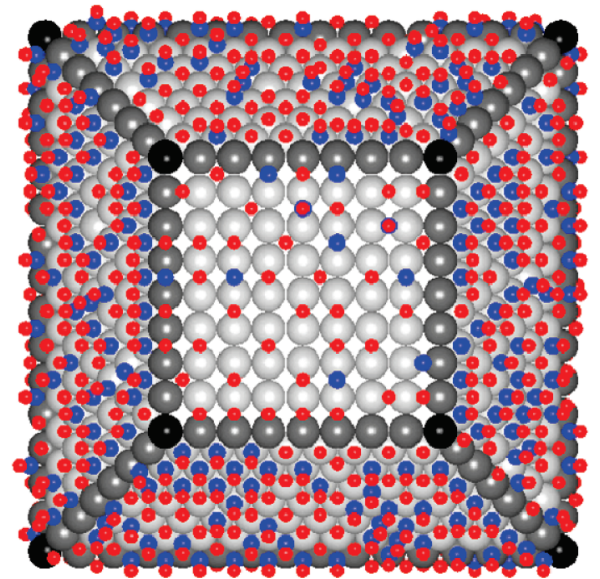

Figure 1. Snapshot from the NO reduction simulation over the $(16 \times 15)$ $\mathrm{Pt}$ nanoparticle under steady-state reaction condition. Oxygen and nitrogen atoms are shown in red and blue, respectively. The Pt atoms on the facets are light gray; the Pt atoms on the edge boundaries between facets are dark gray and the Pt atoms at the corner sites are black.

surfaces of these particles but neglect any shape transformation and surface reconstruction that might occur under reaction conditions. We also assume that particle shape remains the same as the particle size increases. Four different size nanoparticles were studied in this work, each of which is represented by the total number of atoms along the width of its widest side $(L)$ and the total number of height layers $(H)$. The particle size shown in Figure 1, for example, is designated as the $(16 \times 15)$ cluster as it is 16 atoms wide along the center and 15 layers high. Table 1 lists the total number of atoms for each particle, the total number of surface atoms, and the numbers of atoms on the (100) and the (111) facets, as well as the number of atoms on the edge and the corner sites of four model Pt nanoparticles used in this work. By increasing particle size, we increase the area of the (111) facets exposed over the particle surface while the atomic ratios of the (100) facet compared to the overall surface remains about the same (Figure 2). To compare changes that might occur as a result of nonsymmetrical particle growth, we examined the $(20 \times 7) \mathrm{Pt}$ nanoparticle which has about the same number of bulk and surface Pt atoms as the $(16 \times 15)$ particle. The atomic ratio of the $(100)$ facet, however, is $32 \%$ on the $(20 \times 7)$ particle as compared to only $6.7 \%$ on the $(16 \times 15)$ particle (see Table 1$)$. The diameter of the model particle $\left(D_{\text {particle }}\right)$ is determined by eq 1 established using a spherical particle assumption

$$
D_{\text {particle }}=d_{\text {atom }} \times\left(N_{\text {total }}\right)^{1 / 3}
$$

where $d_{\text {atom }}$ is the diameter of the Pt atom $(=0.278 \mathrm{~nm})$ and $N_{\text {total }}$ is the total number of $\mathrm{Pt}$ atoms in the particle. The calculated diameters of the model particles examined are given in Table 1.

2.2. Intrinsic Kinetics from First-Principles Calculations. The intrinsic kinetics database used as input for the kinetic Monte Carlo simulations was established by carrying out ab initio DFT calculations on all of the reactants, products, and proposed intermediates. More specifically, we calculated the adsorption energies for $\mathrm{NO}, \mathrm{N}, \mathrm{O}, \mathrm{NO}_{2}, \mathrm{O}_{2}$, and $\mathrm{N}_{2} \mathrm{O}$ as well as the overall reaction energies and activation barriers for the key elementary steps in the reaction mechanism on the (100), (111), and the stepped (211) surfaces using the VASP code. ${ }^{18,19}$ The Perdew-Wang form of the generalized gradient approximation (GGA) was used to describe exchange and correlation energies. ${ }^{20}$ Ultrasoft pseudopotentials with a cutoff 
Table 1. Distribution of Surface and Bulk Atoms for the Different Truncated Octahedral Pt Nanoparticles Used to Carry out NO Reduction Simulations

\begin{tabular}{|c|c|c|c|c|c|c|c|c|c|c|}
\hline $\begin{array}{c}\text { particle } \\
\text { size }(L \times H)\end{array}$ & $\begin{array}{l}\text { diameter } \\
(\mathrm{nm})\end{array}$ & $N_{\text {total }}$ & $N_{\text {surface }}$ & $N_{(100)}$ & $N_{(111)}$ & $N_{(111) /(100) \text { edge }}$ & $N_{(111) /(111) \text { edge }}$ & $N_{\text {corner }}$ & $N_{(100)} / N_{\text {surface }}$ & $N_{(111)} / N_{\text {surface }}$ \\
\hline $10 \times 9$ & 2.29 & 560 & 260 & 16 & 144 & 16 & 56 & 12 & 0.062 & 0.554 \\
\hline $14 \times 13$ & 3.22 & 1554 & 544 & 36 & 360 & 24 & 88 & 12 & 0.066 & 0.662 \\
\hline $16 \times 15$ & 3.68 & 2328 & 725 & 49 & 504 & 28 & 104 & 12 & 0.068 & 0.695 \\
\hline $20 \times 19$ & 4.61 & 4570 & 1165 & 81 & 864 & 36 & 136 & 12 & 0.069 & 0.742 \\
\hline $20 \times 7$ & 3.68 & 2348 & 709 & 225 & 264 & 60 & 88 & 12 & 0.317 & 0.377 \\
\hline
\end{tabular}

energy of $320 \mathrm{eV}$ were used to calculate the electron-ion energies. The metal surface was described by a periodic supercell that contains four metal layers along with a $12 \AA$ vacuum layer to electronically separate the repeating slab structure in the $z$-direction. The top three layers of the slab as well as adsorbate adlayer were allowed to optimize to minimizing the total energy. The bottom layer of the slab was held fixed at the bulk lattice spacing of the metal. Transition states were isolated using the nudged elastic band method. ${ }^{21}$ The resulting binding energies of all surface intermediates on the (100) and (111) surfaces are given in Table 2. The binding energies of $\mathrm{N}, \mathrm{O}$, and $\mathrm{NO}$ on the edge $(111) /(100)$ sites are taken from the step sites on the stepped (211) surface. Previous DFT studies found that NO reduction is enhanced on the stepped $\operatorname{Ir}(211)$ surface $^{22}$ which is consistent with the results found here for NO dissociation on $\mathrm{Pt}(211)$. NO oxidation barriers at these sites are higher as a result of the stronger adsorbate interactions. DFT calculations also provided the geometric information to represent the structures for all the adsorbates on the surface in the explicit-site kinetic Monte Carlo algorithm. The intrinsic activation barriers for each of the elementary reaction steps on

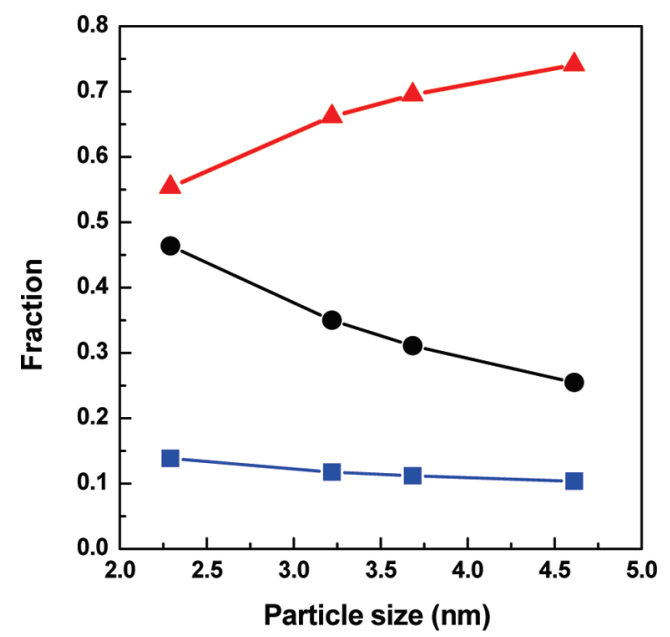

Figure 2. Ratio of different atoms within the model truncated octahedral Pt nanoparticles as a function of the particle size. (@) $N_{\text {surface }} / N_{\text {particle }}$; (ם) $N_{100} / N_{\text {surface }} ;(\boldsymbol{\Delta}) N_{111} / N_{\text {surface }}$. the different surfaces are given in Table 3. Zero-point energy corrections were not explicitly included in the calculations. More details on the DFT calculations and their results can be found in a previous publication. ${ }^{14}$

Although the intrinsic kinetics are important, the local reaction environment can significantly alter the actual rate. Herein we examine the influence of local surface coverage on the kinetics and establish a model that can be used within the kinetic simulations to predict the interactions that occur between adsorbed intermediates. Lateral interactions are composed of through-space interactions that result from Coulombic and/or steric interactions between two or more adsorbates, and throughsurface interactions that result from electronic interactions between coadsorbates that occur through the metal surface. Experimental studies of NO temperature-programmed desorption and calorimetric measurements on different Pt surfaces have shown that lateral interactions are significant and cannot be neglected. ${ }^{23,24}$ The strong repulsive interactions between the $\mathrm{O}-\mathrm{O}$ and the $\mathrm{O}-\mathrm{NO}$ pairs on $\mathrm{Pt}$ surfaces have been studied using first-principles calculations. ${ }^{14-16,25,26}$ The through-space interactions are modeled herein by using a van der Waals (vdW) interaction model taken from the Merck molecular force field. ${ }^{27}$ The through-surface interactions were calculated using a DFTbased bond order conservation (BOC) method. ${ }^{16,28-35}$ The DFTbased BOC model was constructed by parametrizing a bond order conservation model with DFT results taken at different coverages. More specifically, the binding energies for adsorbed $\mathrm{O}, \mathrm{N}$, and $\mathrm{NO}$ on the (100) and the (111) surfaces were calculated from DFT at different coverages and in different atomic configurations. This includes different coadsorption configurations for $\mathrm{O}-\mathrm{NO}, \mathrm{O}-\mathrm{N}$, and $\mathrm{NO}-\mathrm{N}$ surface intermediates. This parametrized BOC model is subsequently used together with the through-space $\mathrm{vdW}$ interaction model directly within the simulations to determine the influence the local adsorbed intermediates have on the local elementary kinetics at each point in time. These models collectively capture the local interactions that occur between different surface species. The VDW and BOC models focus solely on the interactions between the adsorbed intermediates and not the transition states, they therefore underestimate the repulsive interactions that result on the single crystal surfaces but tend to better represent the

Table 2. DFT-Calculated Atomization Energies (kJ/mol) and Binding Energies (kJ/mol) for All Reactant, Intermediate, and Product Molecules on $\operatorname{Pt}(100)$ and $\operatorname{Pt}(111)$ Surfaces and the (111)/(100) Edge Sites ${ }^{a}$

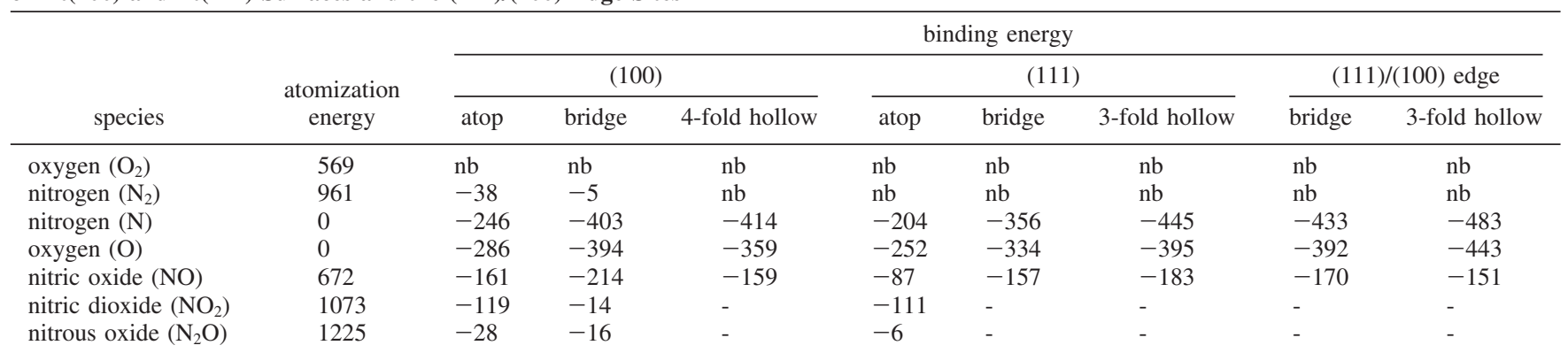

${ }^{a}$ The abbreviation "nb" indicates that there is no adsorption state for the species, whereas "-" indicates that the binding energy for the species at the specific site was estimated using the BOC model within the simulation. 
Ind. Eng. Chem. Res., Vol. 49, No. 21, 201010367

Table 3. DFT-Calculated Activation Barriers $(\mathrm{kJ} / \mathrm{mol})$ for the Elementary Reactions over Pt (100) and Pt(111) Surfaces and (111)/(100) Edge Sites $^{a}$

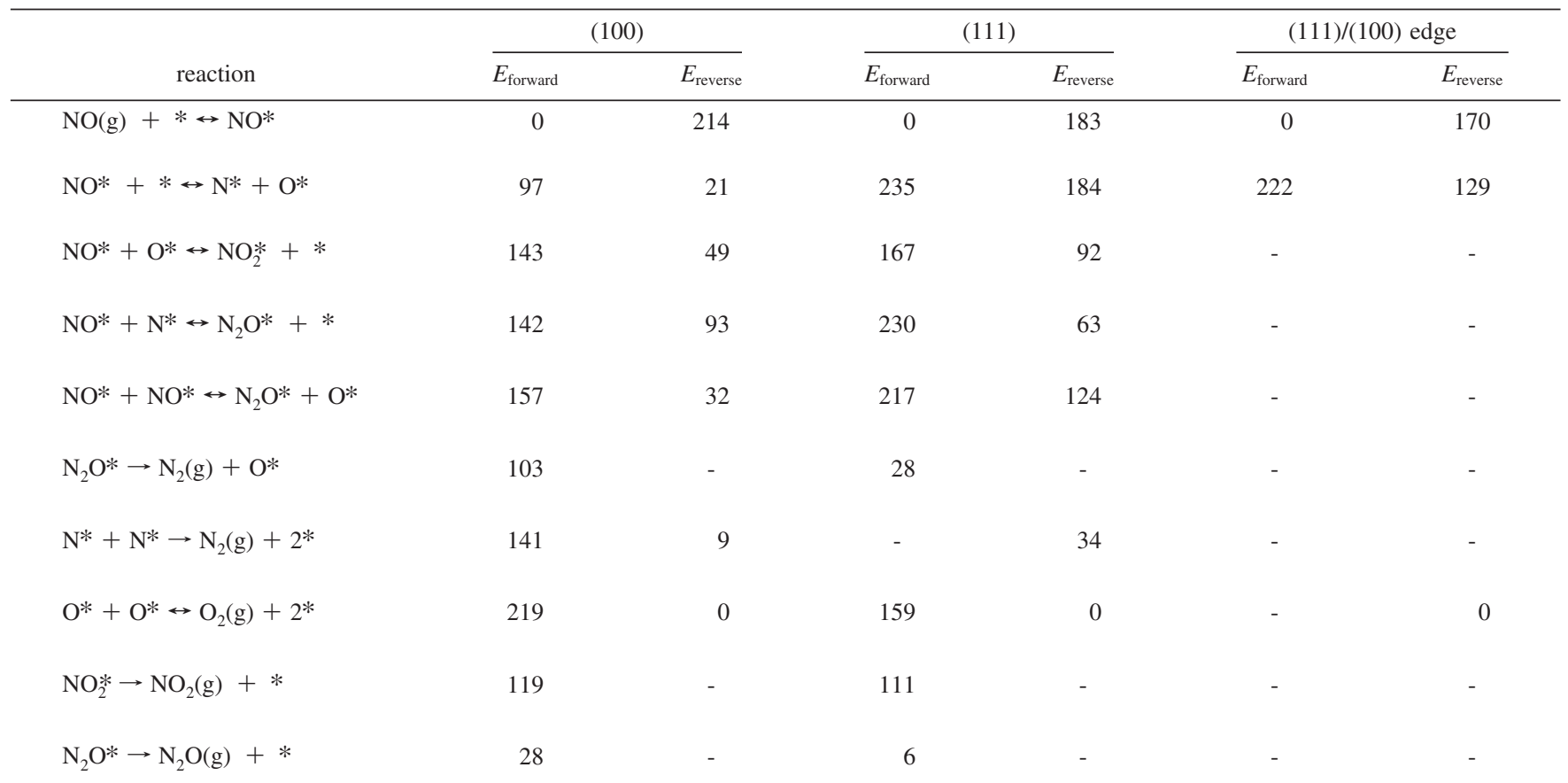

${ }^{a}$ The symbol "-" indicates that the activation barrier and reaction energy were estimated using the BOC Model within the simulations.

weaker interactions that occur on actual particles that are not constrained laterally. As such they provide a better match to the higher coverages that are found on supported nanoparticles as compared to the single crystal surfaces. They are also consistent with recent theoretical results which indicate $1 \mathrm{ML}$ coverages of oxygen on Pt clusters. ${ }^{36}$

2.3. Reaction Mechanism. The reaction mechanism for lean NO reduction given in Table 3 was constructed based upon our previous theoretical results ${ }^{15,16}$ as well as experimental results reported in the literature. ${ }^{37}$ Vacant surface sites are defined as * whereas $i *$ refers to the sites occupied by species $i$. The first step in the mechanism involves the adsorption of NO which can occur at all sites (atop, bridge, hollow sites) on the particle. $\mathrm{NO}^{*}$ can dissociate into atomic $\mathrm{N}^{*}$ and $\mathrm{O}^{*}$, or react with neighboring $\mathrm{O}^{*}$ or $\mathrm{N}^{*}$ to form $\mathrm{NO}_{2}^{*}$ and $\mathrm{N}_{2} \mathrm{O}^{*}$, respectively. The coupling of two $\mathrm{NO}^{*}$ molecules can also occur at higher $\mathrm{NO}^{*}$ coverages and result in the formation of $\mathrm{N}_{2} \mathrm{O}^{*}$ and $\mathrm{O} *$. The adsorbed $\mathrm{N}_{2} \mathrm{O} *$ that results can either desorb from the surface or dissociate to form $\mathrm{O}^{*}$ and $\mathrm{NO} . \mathrm{NO}_{2}{ }^{*}$, on the other hand, was found to be a more stable surface intermediate which can dissociate back to form surface $\mathrm{NO}^{*}$ and $\mathrm{O} *$. This reaction is especially prevalent at higher temperatures and tends to set the oxygen surface coverage. ${ }^{5,38}$ The surface $\mathrm{N}^{*}$ and $\mathrm{O}^{*}$ that form can subsequently recombine with other $\mathrm{N}^{*}$ and $\mathrm{O}^{*}$ to form $\mathrm{N}_{2}$ and $\mathrm{O}_{2}$, respectively, which readily desorb from surface. The $\mathrm{N}^{*}$ and $\mathrm{O}^{*}$ adatoms can also recombine to form $\mathrm{NO}^{*}$ on the surface. In addition to the direct decomposition reactions of $\mathrm{NO}^{*}$ we also consider the dissociative reaction of $\mathrm{O}_{2}$. Recent experimental results suggest that the kinetically relevant step involves the adsorption and diffusion of mobile oxygen species on vacancy sites within an $\mathrm{O}^{*}$ covered surface. ${ }^{39}$ Herein we do not attempt to distinguish whether $\mathrm{O}_{2}$ adsorption or $\mathrm{O}_{2}$ splitting controls the rate but instead consider only the direct dissociative adsorption from the gas phase. Preliminary DFT results suggest that adsorption of oxygen on Pt surfaces at high oxygen coverages can be limiting. The details of these results along with kinetic simulations will be the subject of a future communication.

2.4. Rate Calculation. The reaction rate for each elementary step $r_{i}$ is calculated using transition state theory

$$
r_{i}=v_{i} \exp \left(\frac{-\Delta E_{i}}{R T}\right)
$$

where $v_{i}$ is the pre-exponential factor, which can be calculated by DFT calculations or estimated from statistical mechanics, $R$ is the gas constant, $T$ is the temperature, and $\Delta E_{i}$ is the activation energy barrier for this elementary reaction $i$. The activation barriers of the elementary surface reaction steps have been determined by DFT calculations for the sites on the (100) and the (111) facets as well as the $(111) /(100)$ edge sites. The diffusion barriers are approximated by the hopping energies, i.e., the energy difference between the different stable surface sites. For example, the activation barrier for an adsorbate that moves between the stable 3-fold fcc and hcp sites is simply calculated as the difference in energy between the bridge and the initial fcc (or hcp) site; the barrier to move between two bridge sites is the energy difference between the bridge site and either a 3-fold fcc (or hcp) site on the (111) facet or a 4-fold hollow site on the (100) facet.

The pre-exponential factors, $v_{i}$, were derived from simple statistical mechanical estimates. All of the unimolecular decomposition steps were thus chosen to be $10^{13} \mathrm{~s}^{-1}$ at $500 \mathrm{~K}$ and scaled to the appropriate temperature by the ratio of $(T /$ $500)^{1 / 2}$ based on the changes in collision frequency with temperature derived from collision theory. The pre-exponential factor for bimolecular $A^{*}+B^{*}$ surface reaction, where $A^{*}$ and $\mathrm{B}^{*}$ are immobile, was calculated to be $10^{-2}$ or $10^{-3} \mathrm{~cm}^{2} / \mathrm{s}$ at $500 \mathrm{~K}$ and scaled by $(T / 500)^{1 / 2} \cdot{ }^{24}$ The deterministic rate equation for a bimolecular reaction system, however, must also be multiplied by the site density $\left(10^{15}\right.$ sites $\left./ \mathrm{cm}^{2}\right)$ in order to provide the pre-exponential factor in terms of $\mathrm{s}^{-1}$. As such, the apparent pre-exponential factor for a bimolecular $\mathrm{A}^{*}+\mathrm{B} *$ reaction then 
becomes $10^{13} \mathrm{~s}^{-1}$. This is consistent with both theoretical and experimental values reported in the literature. ${ }^{40}$ The preexponential factor of $10^{13}(T / 500)^{1 / 2} \mathrm{~s}^{-1}$ for desorption is used in this work. This can also be found in most classic statistical mechanical estimations for desorption. ${ }^{40}$ The further distinction between unimolecular and bimolecular steps based on differences in the vibrational modes between the transition and the reactant states is not included herein. This can in principle be determined by detailed first-principles calculations using the explicit forces that act upon each state. ${ }^{41-43}$

The calculation of the adsorption rate is characteristically different from the above elementary surface reaction rate calculations. The adsorption rate for species $i$ is defined as $^{29,30,33,44}$

$$
r_{\mathrm{ad}, i}=s_{0} \cdot P_{i} \cdot A_{\mathrm{S}} \cdot\left(2 \pi \cdot \mathrm{MW}_{i} \cdot R T\right)^{-0.5} \cdot \exp \left(\frac{-\Delta E_{i}}{R T}\right)
$$

where $s_{0}$ is the sticking coefficient, $P_{i}$ is the partial pressure of species $i, A_{\mathrm{s}}$ is the area of one surface site, and $\mathrm{MW}_{i}$ is the molecular weight of species $i$. The sticking coefficients of NO on the (100) and the (111) facets were taken to be 0.7 and 0.6 , respectively. ${ }^{24,45}$ The sticking coefficients of $\mathrm{O}_{2}$ on the (100) and (111) facets were taken to be 0.1 and 0.02 , respectively, based on experimental measurements. ${ }^{46,47}$ The sticking coefficients of $\mathrm{NO}$ and $\mathrm{O}_{2}$ on the edge $(100) /(111)$ sites are assumed to be the same as those on the (111) facet.

2.5. Kinetic Monte Carlo Simulation. The basic construction of the KMC algorithm used herein has been described in previous papers. ${ }^{29,30,33,44}$ We provide a brief discussion hereof the most salient features. The DFT calculated structural, electronic, and energetic properties for all of the reactants, intermediates, and products are used as inputs to the simulation. This includes the binding energies and molecular structures of the adsorbates at all of the possible adsorption sites, vdW radii (physical size) of all of the species, along with the reaction energies and activation barriers for all of the proposed elementary steps. This intrinsic kinetic database is combined with the DFT-parametrized lateral interaction models which include through-surface and through-space interactions into the core reaction kinetic model in the simulation. After initialization, all the sites on the Pt nanoparticle surface are examined in order determine all of the possible kinetic events that can occur on the surface of the particle at any given point in time. These surface events are dependent upon the specific site that is chosen as well as the local environment about the site, which is defined by the number, type, and specific location of neighboring adsorbates. The active sites on the three-dimensional nanoparticle surface include the sites on the top (100) facet, the eight side (111) facets, and four edge (111)/(100) boundaries. We do not simulate the chemistry at the bottom of the particle as it is assumed to be anchored to the support. As a first approximation, the reactions at the edge (111)/(111) boundary sites and the four corner sites were simply treated as (111) sites. We scan the surface at each point in time and sample all possible sites for reaction. At each site, we calculate the binding energies for the adsorbed species as well as the possible "products" at the chosen sites for both initial configuration states and final configuration states. The intrinsic rate constants for each of these events is determined by taking the intrinsic DFT rate constant for the particular event stored within the DFT database and subsequently correcting it via the vdW and DFT-BOC interactions models to account for the lateral interactions that result in the reactant and product states due to their specific location on the surface. These calculated binding energies for both the initial and final states are used to rule out particular events where strong repulsive interactions will override the intrinsic kinetics.

At any instant in time $\left(t_{i}\right)$ the rates for all of the possible events that can occur on the entire particle surface are summed together to determine the total rate $\left(\sum r_{i}\right)$ at that time. The total rate is subsequently used along with the variable time step algorithm given in eq 4 to determine the time $\left(t_{i+1}\right)$ at which the next event on the surface occurs.

$$
\Delta t_{v}=\frac{-\ln (\mathrm{RN})}{\sum_{i} r_{i}}
$$

$\Delta t_{v}$ here refers to the variable time step for the transition from state $i$ to state $i+1,\left(t_{i+1}-t_{i}\right)$, and $\mathrm{RN}$ is a random number between 0 and 1 . The specific reaction that occurs somewhere on the surface of the particle within the calculated time step is chosen based on the cumulative reaction probability distribution:

$$
s_{i}=\frac{r_{i}}{\sum_{i} r_{i}}
$$

Accordingly, the particle surface is updated based on this chosen event. The simulation proceeds in event-space, i.e., event-byevent, whereby the time is updated at each event, thus providing for the temporal changes of the surface chemistry.

The outcome from the simulation includes the detailed structure and composition of the surface adlayer as well as the gas phase product distribution as a function of time and processing conditions. The temporal and spatial resolution of the surface enables us to compute a range of surface properties and macroscopic kinetics including both the overall as well as the site-explicit turnover frequencies (TOFs), apparent activation barriers, surface coverages, binding energies, and other averaged properties. The resulting information can be averaged over the entire particle, over different single crystal facets, and even over specific sites thus allowing for an understanding of the atomic surface structure and molecular surface kinetics that may control structure sensitivity and particle size effects.

\section{Results and Discussion}

Kinetic Monte Carlo simulations were carried out over temperatures and pressures consistent with lean $\mathrm{NO}_{x}$ reduction. The partial pressures of $\mathrm{NO}$ and $\mathrm{O}_{2}$ in the gas phase were fixed at 0.468 and 60.8 Torr, respectively, while the temperature was varied between 500 and $900 \mathrm{~K}$. The simulations were carried out over different Pt particle sizes in order to examine structure sensitivity. The simulations were initiated at the reaction conditions specified and were run out long enough in time where the surface coverages achieve a steady state. The kinetics were recorded only after the steady state was achieved. A typical snapshot of KMC simulation is shown in Figure 1.

3.1. Apparent Reaction Kinetics. The TOFs for reaction products were calculated by explicitly counting the number of each product molecule that desorbs from the particle surface as a function of time. The resulting TOFs for the formation of $\mathrm{N}_{2}$, $\mathrm{NO}_{2}$, and $\mathrm{N}_{2} \mathrm{O}$ from the simulations are given in Table 4. As might be expected, the TOF for $\mathrm{N}_{2}$ increases exponentially with the increasing temperature. The TOF for $\mathrm{NO}_{2}$, however, passes through a maximum at about $800 \mathrm{~K}$ over the temperature range examined. The decrease in the TOF of $\mathrm{NO}_{2}$ at higher temperatures is the result of equilibrium limitations that drive the reverse decomposition of $\mathrm{NO}_{2} *$ to $\mathrm{NO}^{*}$ and $\mathrm{O} * .^{37,48,49}$ The rate 
Table 4. Normalized Turnover Frequencies $\left(\mathrm{Pt}^{-1} \cdot \mathrm{s}^{-1}\right)$ for $\mathrm{N}_{2}, \mathrm{NO}_{2}$, and $\mathrm{N}_{2} \mathrm{O}$ over the Model $(16 \times 15)$ Truncated Pt nanoparticle

\begin{tabular}{|c|c|c|c|c|c|c|c|c|c|}
\hline \multirow[b]{2}{*}{$\mathrm{T}(\mathrm{K})$} & \multicolumn{3}{|c|}{ particle } & \multicolumn{3}{|c|}{ (100) facet } & \multicolumn{3}{|c|}{ (111) facet } \\
\hline & $\mathrm{N}_{2}$ & $\mathrm{NO}_{2}$ & $\mathrm{~N}_{2} \mathrm{O}$ & $\mathrm{N}_{2}$ & $\mathrm{NO}_{2}$ & $\mathrm{~N}_{2} \mathrm{O}$ & $\mathrm{N}_{2}$ & $\mathrm{NO}_{2}$ & $\mathrm{~N}_{2} \mathrm{O}$ \\
\hline 500 & $8.02 \times 10^{-6}$ & $1.60 \times 10^{-4}$ & 0.0 & $7.18 \times 10^{-5}$ & $4.69 \times 10^{-5}$ & 0.0 & 0.0 & $1.82 \times 10^{-4}$ & 0.0 \\
\hline 700 & $1.90 \times 10^{-4}$ & $3.67 \times 10^{-3}$ & $3.12 \times 10^{-5}$ & $1.70 \times 10^{-3}$ & $1.48 \times 10^{-3}$ & $2.79 \times 10^{-4}$ & 0.0 & $4.12 \times 10^{-3}$ & 0.0 \\
\hline 800 & $5.33 \times 10^{-4}$ & $7.43 \times 10^{-3}$ & $4.12 \times 10^{-5}$ & $4.77 \times 10^{-3}$ & $2.84 \times 10^{-3}$ & $4.77 \times 10^{-4}$ & 0.0 & $8.37 \times 10^{-3}$ & 0.0 \\
\hline 900 & $1.04 \times 10^{-3}$ & $3.30 \times 10^{-3}$ & $4.31 \times 10^{-5}$ & $9.29 \times 10^{-3}$ & $2.44 \times 10^{-3}$ & $3.86 \times 10^{-4}$ & 0.0 & $3.56 \times 10^{-3}$ & 0.0 \\
\hline
\end{tabular}

of $\mathrm{N}_{2} \mathrm{O}$ formation was found to be negligible as it is $2-3$ orders of magnitude lower than the rates of $\mathrm{N}_{2}$ and $\mathrm{NO}_{2}$ formation. Using an Arrhenius form to describe the influence of temperature, the simulation results reported in Figure 3 reveal an apparent activation energy for $\mathrm{N}_{2}$ formation of $45 \mathrm{~kJ} / \mathrm{mol}$. Experimentally measured activation barriers regressed from elementary kinetics, in general, depend upon the experimental conditions, as well as the nature of the catalyst (particle size and influence of the support). For example, a wide range of apparent activation barriers from 26 to $222 \mathrm{~kJ} / \mathrm{mol}$ on supported $\mathrm{Pt}$ catalysts and $\mathrm{Pt}$ foils has been reported as was discussed by Amirnazmi and Boudart. ${ }^{38}$ The simulated apparent activation energy for $\mathrm{N}_{2}$ formation is in good agreement with our previously simulation results which reported a barrier of $37 \mathrm{~kJ} /$ mol for $\mathrm{N}_{2}$ formation over the $\mathrm{Pt}(100)$ surface. ${ }^{16}$ As $\mathrm{N}_{2}$ formation occurs exclusively on the (100) facet, it is not surprising that we find a similar barrier for $\mathrm{N}_{2}$ formation. The apparent activation energy of $\mathrm{NO}_{2}$ formation was calculated to be $42 \mathrm{~kJ} / \mathrm{mol}$ which is in very good agreement with the best-fit activation barrier of $40.8 \mathrm{~kJ} / \mathrm{mol}$ reported by Olsson et al. ${ }^{45}$ and the barrier of $39 \pm 6 \mathrm{~kJ} / \mathrm{mol}$ reported by Mulla for $\mathrm{NO}$ oxidation over $\mathrm{Pt} / \gamma-\mathrm{Al}_{2} \mathrm{O}_{3}$ carried out at $510-592 \mathrm{~K}$ in the absence of $\mathrm{NO}_{2}$ in the feed gas catalyst. ${ }^{48,49}$ The simulated rates, which range from $5 \times 10^{-4}$ to $3.6 \times 10^{-3} \mathrm{Pt}^{-1} \mathrm{~s}^{-1}$, are slightly lower than the experimental rates reported by Mulla et al., ${ }^{48,49}$ which are between $3.5 \times 10^{-3}$ and $14.7 \times 10^{-3} \mathrm{Pt}^{-1} \mathrm{~s}^{-1}$.

3.2. Facet-Dependent Kinetics. In addition to the apparent kinetics and overall conversion, the site-explicit KMC simulation allows us to analyze the chemical transformations of surface intermediates on each facet of the model Pt nanoparticle. Figures 4 and 5 show the specific activities for the formation of $\mathrm{N}_{2}$, $\mathrm{NO}_{2}$, and $\mathrm{N}_{2} \mathrm{O}$ on the (100) and the (111) facets. These facetbased activities were calculated on the basis of the number of products only desorbed from each kind of facet and normalized by the number of atoms on each facet. Among the different possible reaction paths, which include NO dissociation, NO

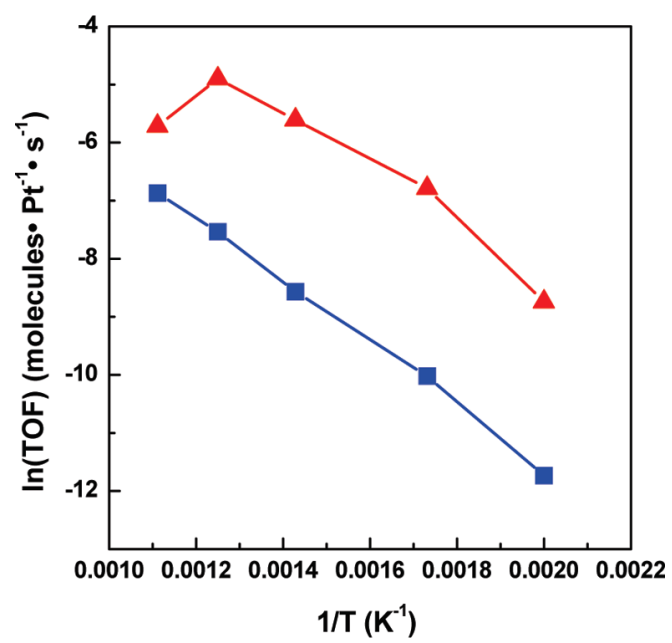

Figure 3. Temperature dependence of the turnover frequencies for $\mathrm{N}_{2}$ and $\mathrm{NO}_{2}$ formation calculated here with respect to the total number of surface Pt atoms over the $(16 \times 15)$ Pt nanoparticle. $(\mathbf{\square}) \mathrm{N}_{2} ;(\boldsymbol{\Delta}) \mathrm{NO}_{2}$. oxidation, $\mathrm{NO}$ coupling, and $\mathrm{N}_{2} \mathrm{O}$ formation, $\mathrm{NO}$ dissociation is the most favorable route as the $\mathrm{N}_{2}$ formation rates are higher than those for the formation of $\mathrm{NO}_{2}$ and $\mathrm{N}_{2} \mathrm{O}$ as seen in Figure 4. The activation barrier for NO dissociation on the (100) facet is $97 \mathrm{~kJ} / \mathrm{mol}$ as determined from DFT calculations, which is $45-50 \mathrm{~kJ} / \mathrm{mol}$ lower than that of the other three paths.

At low temperature, both $\mathrm{NO}$ decomposition to $\mathrm{N}_{2}$ and $\mathrm{NO}$ oxidation to $\mathrm{NO}_{2}$ are the major paths that proceed on the (100) facet. While the barrier for NO decomposition is lower than that for NO oxidation, the dissociation of NO requires the availability of a vicinal free site to allow the reaction to proceed. The oxygen surface coverage at low temperature is relatively high and as result $\mathrm{O}^{*}$ acts to block NO dissociation. Simulation results show an $\mathrm{N}_{2}$ formation rate of $3.98 \times 10^{-4} \mathrm{Pt}^{-1} \mathrm{~s}^{-1}$, which is slightly lower than the simulated $\mathrm{NO}_{2}$ formation rate of 4.34

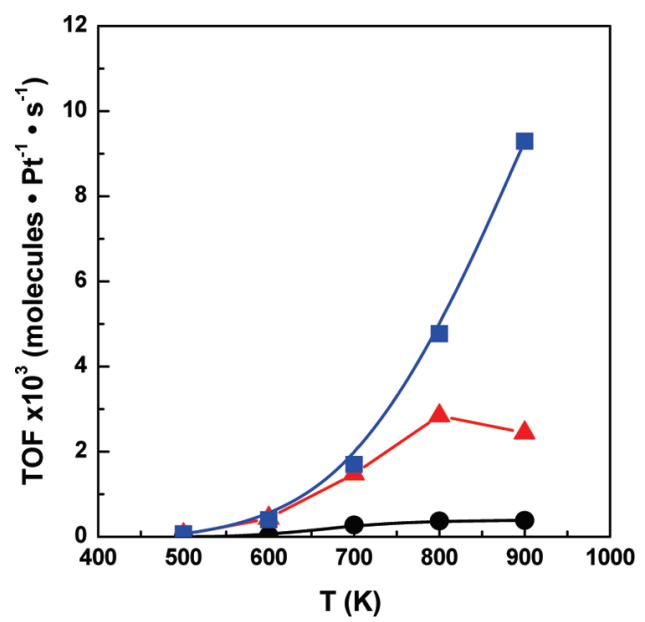

Figure 4. Temperature dependence of the turnover frequencies for $\mathrm{N}_{2}, \mathrm{~N}_{2} \mathrm{O}$, and $\mathrm{NO}_{2}$ formation calculated with respect to the total number of surface $\mathrm{Pt}$ atoms on the $(100)$ facet over the $(16 \times 15)$ Pt nanoparticle. (回) $\mathrm{N}_{2} ;(\bullet)$ $\mathrm{N}_{2} \mathrm{O} ;(\boldsymbol{\Delta}) \mathrm{NO}_{2}$.

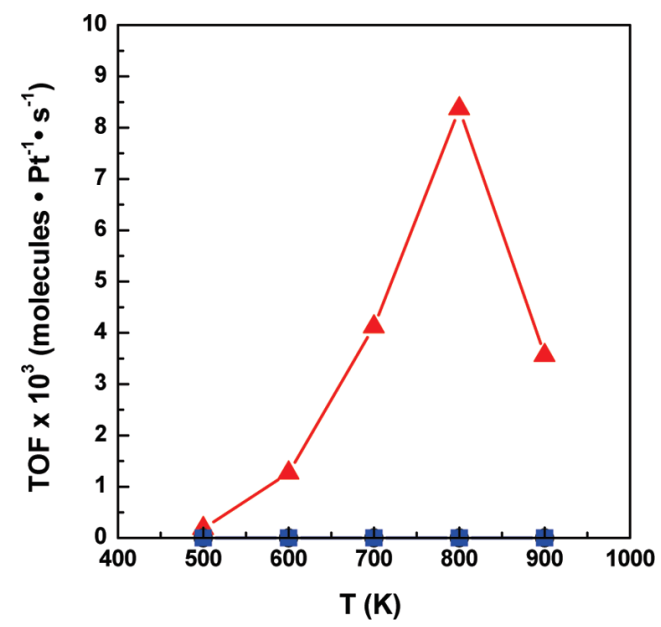

Figure 5. Temperature dependence of the turnover frequencies of $\mathrm{N}_{2}, \mathrm{~N}_{2} \mathrm{O}$, and $\mathrm{NO}_{2}$ formation calculated with respect to the total number of surface $\mathrm{Pt}$ atoms on the $(111)$ facets over the $(16 \times 15) \mathrm{Pt}$ nanoparticle. $(\boldsymbol{\square}) \mathrm{N}_{2}$; (•) $\mathrm{N}_{2} \mathrm{O} ;(\boldsymbol{\Delta}) \mathrm{NO}_{2}$. 


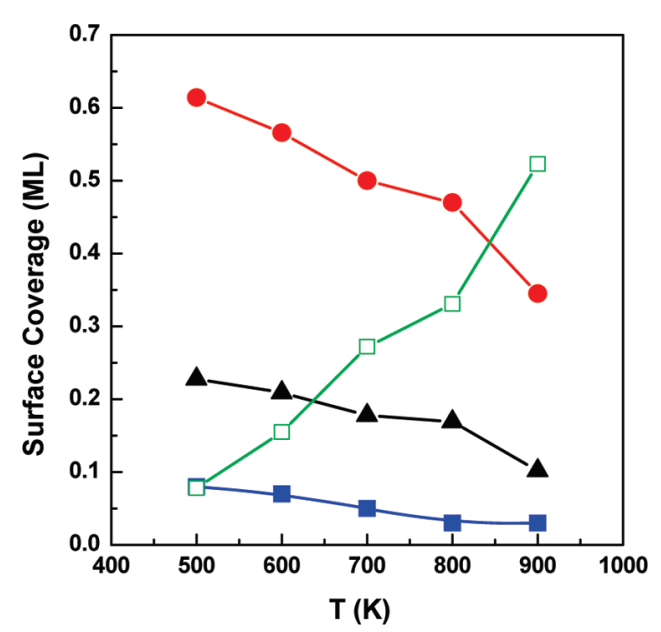

Figure 6. Temperature dependence of the surface coverages of NO, N, and $\mathrm{O}$ averaged over the total number of surface $\mathrm{Pt}$ atoms on the $(16 \times 15)$

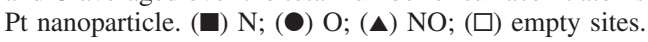

$\times 10^{-4} \mathrm{Pt}^{-1} \mathrm{~s}^{-1}$ at $600 \mathrm{~K}$. As the temperature increases, the surface coverage of oxygen dramatically decreases as a result of thermodynamics which shifts the equilibrium between $\mathrm{NO}^{*}$ $+\mathrm{O}^{*}$ and $\mathrm{NO}_{2} *$ back to $\mathrm{NO}^{*}$ and $\mathrm{O} *$. This results in more vacant sites on the (100) facets which increases the NO decomposition rate and enhances $\mathrm{NO}$ dissociation over NO oxidation on these specific sites. At $800 \mathrm{~K}$, the $\mathrm{N}_{2}$ formation rate on the (100) sites is nearly two times higher than for the formation of $\mathrm{NO}_{2}$.

$\mathrm{N}_{2} \mathrm{O}$ can also be formed either by the coupling of two NO molecules or the by the reaction of $\mathrm{NO}^{*}+\mathrm{N}^{*}$. The resulting $\mathrm{N}_{2} \mathrm{O}$ is weakly held to the surface and readily desorbs. The rate for $\mathrm{N}_{2} \mathrm{O}$ formation on the (100) facet was found to be very low. $\mathrm{N}_{2} \mathrm{O}$ formation appears to be limited by its relatively high activation barriers of 142 and $157 \mathrm{~kJ} / \mathrm{mol}$ as well as low surface converges of $\mathrm{NO}^{*}$ and $\mathrm{N}^{*}$.

As shown in Figure 5, we found that $\mathrm{NO}_{2}$ is the only significant product that forms on the (111) facets. This is not surprising since the 111 surface of $\mathrm{Pt}$ is relatively inactive for NO dissociation. ${ }^{5}$ Our DFT results indicate that the reaction barrier for NO oxidation on the $\mathrm{Pt}(111)$ surface is $167 \mathrm{~kJ} / \mathrm{mol}$ while the barriers for NO dissociation and NO coupling are 235 and $217 \mathrm{~kJ} / \mathrm{mol}$, respectively. The higher reaction barriers and the high oxygen coverage on the (111) facet prohibit the formation of $\mathrm{N}_{2}$ and $\mathrm{N}_{2} \mathrm{O}$. The simulations here reveal that the $\mathrm{NO}_{2}$ formation rate increases with the increasing temperature up until $800 \mathrm{~K}$ on both the (100) and the (111) facets. This indicates that $\mathrm{NO}_{2}$ can be formed over the surface of the $\mathrm{Pt}$ particle through a Langmuir-Hinshelwood type mechanism. Our theoretical results indicate that the intrinsic activation barrier for an Eley-Rideal mechanism would be greater than $170 \mathrm{~kJ} /$ mol and thus rule out this mechanism.

3.3. Surface Coverages. The KMC simulations also provide detailed spatiotemporal information that can be used to determine the sites and facets that are active for specific reactions. The resulting adsorbate surface coverages can be normalized by the number of Pt atoms on the specific facet and also by the total number of surface atoms of the Pt particle. The uncertainty of the averaged surface coverages reported here is less than $5 \%$. The temperature dependent surface coverages for $\mathrm{N}^{*}, \mathrm{O}^{*}, \mathrm{NO}^{*}$, $\mathrm{N}_{2} \mathrm{O} *$, and $\mathrm{NO}_{2} *$ averaged with respect to the total number of $\mathrm{Pt}$ atoms, the number of $\mathrm{Pt}$ atoms that make up the (111) sites, and the number of Pt atoms that make up the (100) sites, are presented for the $3.7 \mathrm{~nm}$ (e.g., $16 \times 15$ ) particle in Figures 6, 7 , and 8 respectively. Regardless of the temperature chosen,

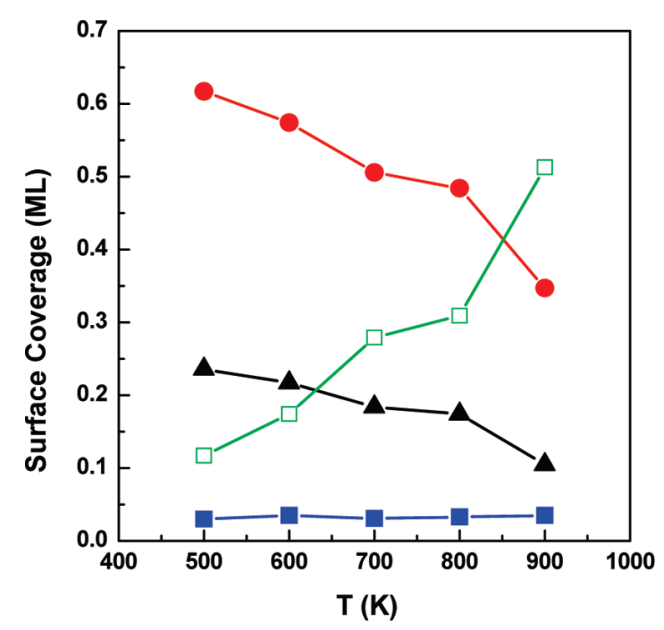

Figure 7. Temperature dependence of the surface coverages of NO, N, and $\mathrm{O}$ averaged over the total number of $\mathrm{Pt}$ within the (111) surface facets on the $(16 \times 15)$ Pt nanoparticle. $(\square) \mathrm{N} ;(\boldsymbol{O}) \mathrm{O} ;(\boldsymbol{\Delta}) \mathrm{NO}$; $(\square)$ empty sites.

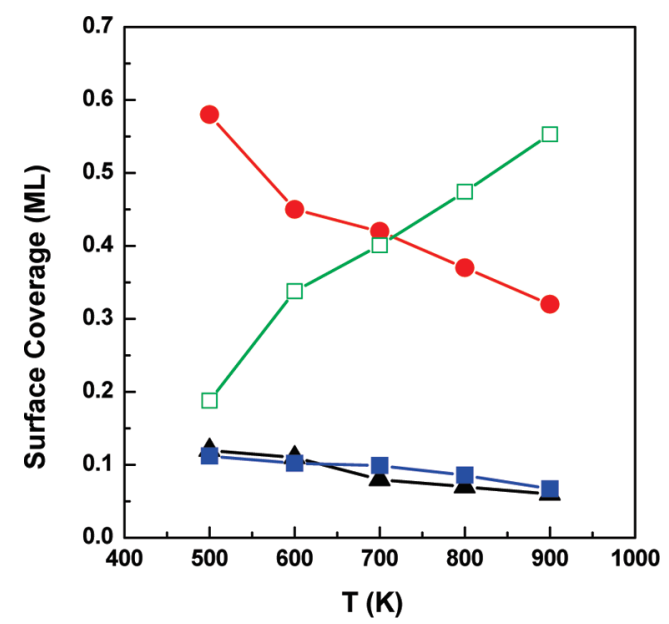

Figure 8. Temperature dependence of the surface coverages of NO, N, and $\mathrm{O}$ averaged over the total number of $\mathrm{Pt}$ atoms within the (100) surface facets on the $(16 \times 15)$ Pt nanoparticle. $(\square) \mathrm{N} ;(\boldsymbol{O}) \mathrm{O} ;(\boldsymbol{\Delta}) \mathrm{NO} ;(\square)$ empty sites.

the steady state surface coverages of $\mathrm{N}_{2} \mathrm{O} *$ and $\mathrm{NO}_{2} *$ were found to be negligible. While the $\mathrm{NO}_{2}{ }^{*}$ coverage is negligible, it readily forms and desorbs or dissociates back to form $\mathrm{NO}^{*}$ and $\mathrm{O}^{*}$. As was shown experimentally, the reaction of $\mathrm{NO}^{*}+\mathrm{O}^{*}$ $\rightarrow \mathrm{NO}_{2} *$ controls the surface coverage of oxygen. ${ }^{50,51}$

The temperature dependent steady-state coverages of NO*, $\mathrm{N}^{*}$, and $\mathrm{O}^{*}$ averaged over the entire $\mathrm{Pt}$ particle are shown in Figure 6. The results indicate that the particle is predominately covered by oxygen which is consistent with experimental results reported for reduction ${ }^{52}$ and NO oxidation. ${ }^{50,51}$ As the temperature increases from 500 to $900 \mathrm{~K}$, the surface coverage of oxygen decreases by almost a factor of 2 from 0.62 down to $0.35 \mathrm{ML}$. The coverage of NO also decreases by about a factor of 2 from $0.24 \mathrm{ML}$ at $500 \mathrm{~K}$ to $0.11 \mathrm{ML}$ at $900 \mathrm{~K}$. The atomic nitrogen coverage over the entire particle surface is quite low, ranging from just $0.03-0.07 \mathrm{ML}$ over the temperatures studied. The total surface coverage therefore also decreases by nearly a factor of 2 from 0.87 to $0.48 \mathrm{ML}$ as the temperature is increased from 500 to $900 \mathrm{~K}$. This results in a significant increase in the number of vacant sites.

To elucidate the influence of structure, we examined the explicit surface coverages on each facet. As the (111) facets dominate the exposed surface area, the temperature dependence of the coverages of $\mathrm{NO}^{*}, \mathrm{O}^{*}$, and $\mathrm{N}^{*}$ on the (111) facets shown 


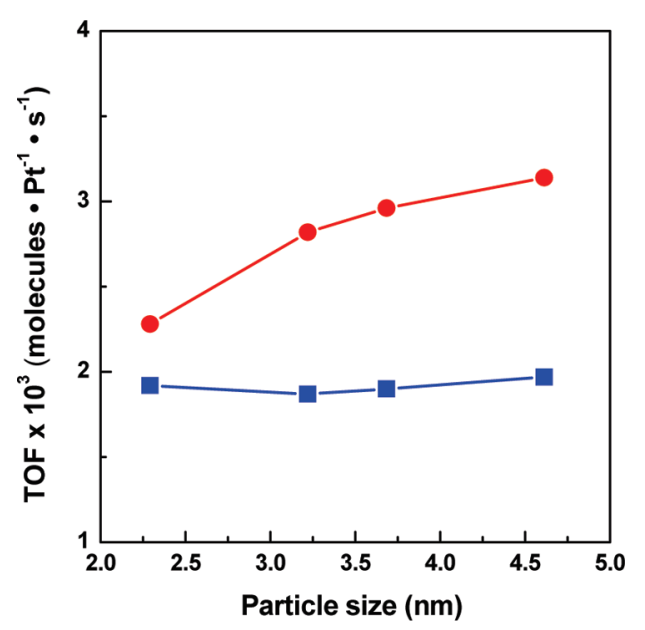

Figure 9. Effect of particle size on the $\mathrm{N}_{2}$ and $\mathrm{NO}_{2}$ formation rates normalized on the basis of the total number of surface atoms on the $\mathrm{Pt}$ nanoparticles. (ロ) $\mathrm{N}_{2} ;(\bullet) \mathrm{NO}_{2}$.

in Figure 7 very closely mimic those presented in Figure 6 over the entire Pt particle. Oxygen binds strongly to surface and occupies $0.61 \mathrm{ML}$ at $500 \mathrm{~K}$. The $\mathrm{O} *$ coverage decreases to 0.35 $\mathrm{ML}$ as the temperature is increased to $900 \mathrm{~K}$. The activation barriers to dissociate NO on the (111) surface are prohibitively high thus resulting in negligible $\mathrm{N}^{*}$ coverages. $\mathrm{NO}^{*}$, on the other hand, readily adsorbs and fills in many of the surface vacancies leading to an $\mathrm{NO}^{*}$ surface coverage of $0.23 \mathrm{ML}$ at $500 \mathrm{~K}$. As the temperature is increased to $900 \mathrm{~K}$, the NO* coverage drops to $0.10 \mathrm{ML}$ as a result of desorption.

Although the surface coverages on the (100) facets demonstrate qualitative behavior similar to those found on the (111) facets, there are distinctive differences between the two surfaces that lead to significantly different reactivity on them. As was found on the (111) facets, oxygen is the dominant intermediate on the (100) facets with the $\mathrm{O}^{*}$ coverages ranging from 0.58 $\mathrm{ML}$ at $500 \mathrm{~K}$ to $0.32 \mathrm{ML}$ at $900 \mathrm{~K}$ as shown in Figure 8. The O* coverage on the (100) facet, however, decreases much more significantly than on the (111) facets as the temperature increased to $800 \mathrm{~K}$. The $\mathrm{O} *$ coverage on the (100) facet at 800 $\mathrm{K}$, for example, was found to be only $0.38 \mathrm{ML}$ while that on the (111) facets was $0.46 \mathrm{ML}$. The higher $\mathrm{O}^{*}$ coverage on the (111) surface over that on the (100) facet is likely the result of the higher NO oxidation barrier on the (111) facet compared to that on the (100) facet. The higher barrier can be attributed to the stronger binding energy of $\mathrm{O}^{*}$ at the 3 fold sites of the 111 surface over the bridge and 4 fold sites present on the 100 surface. At $900 \mathrm{~K}$, both (100) and (111) facets have similar O* coverages as the NO reaction becomes equilibrium limited on both facets.

In addition to oxygen, there are also significant differences in the $\mathrm{NO}^{*}$ and $\mathrm{N}^{*}$ coverages on the (100) and (111) facets. NO* readily dissociates on the (100) facets as the temperature is increased from 500 to $800 \mathrm{~K}$ whereas $\mathrm{NO}^{*}$ remains intact on the (111) surface. As such, the NO* surface coverage is significantly lower on the (100) facets. At $500 \mathrm{~K}$, the NO* coverage on the (100) facet was found to be $0.12 \mathrm{ML}$ (Figure 9) which is only half of that (0.24 ML NO*) found on the (111) facet (Figure 7). Similar differences in the NO* coverages on the (100) and (111) facets exist over the full range of temperatures examined. The NO* coverages on the (100) facets are lower than those on the (111) facets since NO* dissociates to $\mathrm{N}^{*}$ and $\mathrm{O}^{*}$ on the $(100)$ facets whereas $\mathrm{NO}^{*}$ remains intact on the (111) surfaces. At higher temperatures, the $\mathrm{N}^{*}$ atoms that form on the (100) facet readily recombine to form $\mathrm{N}_{2}(\mathrm{~g})$.

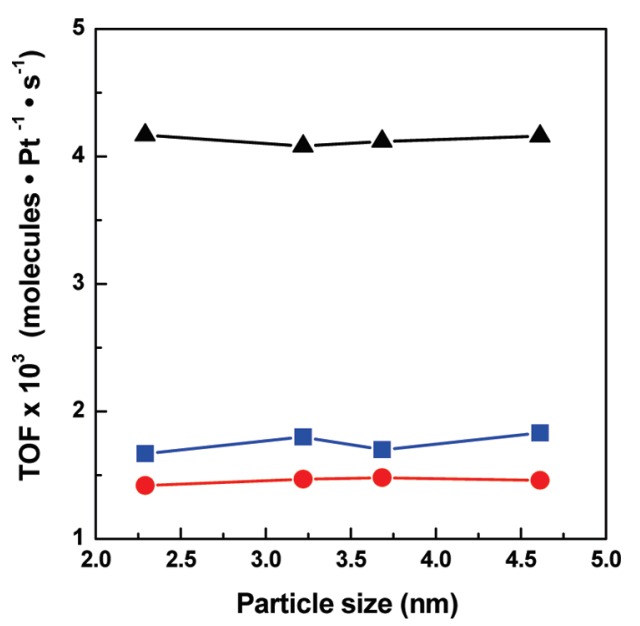

Figure 10. Effect of particle size on the $\mathrm{N}_{2}$ and $\mathrm{NO}_{2}$ formation rates normalized on the basis of the total number of atoms within each facet. (ם) $\mathrm{N}_{2}$ formation on the (100) facet; $(\mathbf{O}) \mathrm{NO}_{2}$ formation on the (100) facet; (A) $\mathrm{NO}_{2}$ formation on the (111) facet.

This results in a higher concentration of vacancies on the (100) facet than what was found on the (111) facet which further promotes NO dissociation on these facets.

Higher temperatures significantly increase the desorption of NO from both the (111) and the (100) facets as well as the associative desorption of $\mathrm{N}_{2}$ from the (100) facet which results in lower surface coverages and increased vacancies as is shown in Figures 7 and 8 for the (111) and (100) facets, respectively. The increase in the number of vacant sites promotes the dissociation of NO over the (100) facet as well as the formation of $\mathrm{N}_{2}$. The increased desorption of $\mathrm{NO}$ along with the enhanced rate for the associative desorption of $\mathrm{N}_{2}$ decreases the $\mathrm{N}^{*}$ surface coverage from 0.12 to $0.06 \mathrm{ML}$ as shown in Figure 8. This decrease in the $\mathrm{N}^{*}$ coverage with temperature ultimately decreases the rate of $\mathrm{N}_{2}$ formation. This is in contrast to results found on the (111) facets shown in Figure 7 whereby the $\mathrm{N}^{*}$ coverage is very low and remains nearly constant.

3.4. Particle Size Effect. The differences in the chemistry on the (111) and (100) facets reported above are structural in nature and will likely lead to the particle size effects. We examine such effects here by simulating NO reduction over different Pt nanoparticles at $700 \mathrm{~K}$ and the same partial pressures of NO (0.468 Torr) and $\mathrm{O}_{2}$ (60.8 Torr) used above. The four truncated octahedral Pt nanoparticles $(2.3-4.6 \mathrm{~nm}$ in diameter) were used in the simulations to examine particle size effects. The results presented in Figures 9 and 10 show the effects of particle size on both the rates of $\mathrm{N}_{2}$ and $\mathrm{NO}_{2}$ formation where the rates are normalized to the total number of metal surface atoms and the number of surface metal atoms within a particle facet, respectively. The results presented in Figure 9, which are based on the overall number of surface Pt atoms, suggest that the rates of $\mathrm{N}_{2}$ formation are nearly independent of particle size. This is inconsistent with the fact that this reaction is specific to the (100) facets. The particle size independence that results is due to the fact that there is little change in the surface area of the (100) facets with increasing particle size. This can be seen in Table 1, which indicates that the percentage of exposed 100 atoms increases by only $0.7 \%$ (from $6.2 \%$ to $6.9 \%$ ) as the particle size increases from 2.3 to $4.6 \mathrm{~nm}$. The relatively small change in the fraction of the exposed (100) sites with particle size may be the result of the symmetric manner in which the particle size was increased. We suspect that there will be significant particle size effect if there is an asymmetry in the expansion of the particle as the particle size is increased. To 
confirm this idea, we carried out simulations over a $(20 \times 7)$ nanoparticle which has an equivalent diameter $(3.68 \mathrm{~nm})$ to that of the $(16 \times 15)$ nanoparticle but has a significantly larger percentage of the (100) sites $(31.7 \%$ versus $6.2 \%)$ of the (100) sites. The simulated $\mathrm{N}_{2}$ formation rate for the $(20 \times 7)$ particle was found to be $5.04 \times 10^{-4} \mathrm{Pt}^{-1} \mathrm{~s}^{-1}$, which is five times higher than the rate of $1.01 \times 10^{-4} \mathrm{Pt}^{-1} \mathrm{~s}^{-1}$ for the $(16 \times 15)$ particle.

A more accurate measure of structure sensitivity would require normalizing the rates to the fraction of the sites on which the reactions actually occur rather than the total number of sites. As such, we report the rates for both NO reduction and NO oxidation on a per site basis in Figure 10. The results show that the simulated $\mathrm{N}_{2}$ formation rates over the (100) facets are $1.67 \times 10^{-3}, 1.79 \times 10^{-3}, 1.70 \times 10^{-3}$, and $1.81 \times 10^{-3} \mathrm{Pt}^{-1}$ $\mathrm{s}^{-1}$ for the particle sizes of $2.3,3.2,3.7$, and $4.6 \mathrm{~nm}$, respectively. The specific activities of NO decomposition over the (100) facets are essentially the same (within the simulation fluctuations) for different sizes of Pt particles. The rates for NO reduction over the (111) facets were found to be zero over all particle sizes. The results here clearly show that there is structure sensitivity for NO reduction reaction which is consistent with experimental results by Burch and Millingston, ${ }^{53}$ Demicheli, ${ }^{1}$ and Denton. ${ }^{2}$ In addition, the results suggest that the use of particle size effects to establish structure sensitivity can be misleading if the changes in specific sites or relative surface areas are not known. This may in fact help to explain some of the reported differences in the structure sensitivity of NO reduction reaction.

The simulation results presented in Figure 9 indicate that NO oxidation is much more structure sensitive than $\mathrm{NO}$ reduction. There is a nearly linear increase in the rate of $\mathrm{NO}_{2}$ formation as the particle size is increased. This is because NO oxidation can occur over both the (100) and the (111) facets of the Pt nanoparticles. The $\mathrm{NO}_{2}$ formation rates presented in Figure 9 and normalized per total surface atom, increase from $2.28 \times$ $10^{-3}$ to $3.14 \times 10^{-3} \mathrm{Pt}^{-1} \mathrm{~s}^{-1}$ as the particle size increased from 2.3 to $4.6 \mathrm{~nm}$ at $700 \mathrm{~K}$. This is consistent with previous experimental results that indicate that larger particles show higher NO oxidation activity. ${ }^{7,48,49}$ The specific activity for $\mathrm{NO}_{2}$ formation on the (100) and the (111) facets was determined by normalizing to the number of these sites. The results, which are shown in Figure 10, indicate that the rates over the (111) and (100) surfaces are essentially constant with particle size with specific activities on the (111) and the (100) surfaces of $4.10 \times 10^{-3}$ and $1.45 \times 10^{-3} \mathrm{Pt}^{-1} \mathrm{~s}^{-1}$, respectively. The $\mathrm{NO}_{2}$ formation rates on the (111) facets reported here are nearly three times higher than that on the (100) facets even though the intrinsic activation barrier for NO oxidation is $24 \mathrm{~kJ} / \mathrm{mol}$ higher on the (111) facets. The higher rates on the (111) facet as compared to the (100) facet are the result of the higher oxygen coverages as well as a higher equilibrium constant on the (111) facet.

NO oxidation rates increase with increasing particle size as was shown in Figure 10 and as such demonstrate significant structure sensitivity. This is due to the higher rates of reaction NO oxidation on the (111) facets along with the increased fraction of (111) sites as the particle size increases. The fraction of (111) sites, for example, increases from $55.4 \%$ to $74.2 \%$ in moving from the $2.3 \mathrm{~nm}(10 \times 9)$ to the $4.6 \mathrm{~nm}(20 \times 19) \mathrm{Pt}$ particle as shown in Table 1. This increase in NO oxidation activity with the increase in cluster size is well established experimentally. ${ }^{7,48,49}$

\section{Conclusions}

A first-principles-based kinetic Monte Carlo simulation was constructed and used to follow the kinetics and structure sensitivity for NO reduction over Pt nanoparticles under lean operating conditions. The results indicate that the reduction of NO to $\mathrm{N}_{2}$ occurs only over the (100) facets which allow for the dissociation of NO with a barrier that is over $100 \mathrm{~kJ} / \mathrm{mol}$ lower on the (100) facets than that on the (111) facets. The (100) sites are unique for $\mathrm{NO}$ activation as they separate $\mathrm{N}^{*}$ and $\mathrm{O} *$ in the transition state which helps to lower the activation barrier. Under lean condition, however, $\mathrm{NO}$ oxidation to $\mathrm{NO}_{2}$ tends to be the dominant reaction path due to the high surface coverages of oxygen which block the surface sites and increase the barriers for NO dissociation as well as NO coupling. As the temperature increases, the rates of formation of $\mathrm{N}_{2}$ and $\mathrm{NO}_{2}$ increase. The simulated apparent activation energies for $\mathrm{N}_{2}$ and $\mathrm{NO}_{2}$ formation over the $3.68 \mathrm{~nm}$ Pt particle are 45 and $42 \mathrm{~kJ} / \mathrm{mol}$, respectively, which is in reasonable agreement with experimental results over Pt.

The catalytic activities for NO reduction and oxidation were determined by the specific sites that catalyze these reactions. For the truncated octahedral Pt clusters examined herein, the fraction of the (111) sites increases with the increasing particle size while the fraction of (100) sites remains about the same. As a result, the NO oxidation activity increases but NO reduction remains the same with the increasing particle size. Clusters, which increase the number of exposed 100 sites, increase the rate of NO reduction. As such, both NO oxidation and NO reduction may be considered structure sensitive, which is consistent with previous experimental observations.

\section{Acknowledgment}

We kindly acknowledge the financial support by NovoDynamics Inc. for this work. The Laboratory Directed Research and Development (LDRD) project under Catalysis Initiative at Pacific Northwest National Laboratory (PNNL) partially supported this work (D.M.). We also gratefully acknowledge the computational support from the Molecular Science Computing Facility (MSCF) in the William R. Wiley Environmental Molecular Sciences Laboratory, a national scientific user facility sponsored by the U.S. Department of Energy's Office of Biological and Environmental Research and located at the Pacific Northwest National Laboratory. Pacific Northwest is operated for the Department of Energy by Battelle. We also thank Dr. Laurent Kieken, Dr. Jan Lerou, Professor Qingfeng Ge, and Professor Enrique Iglesia for many fruitful discussions.

\section{Literature Cited}

(1) Demicheli, M. C.; Hoang, L. C.; Menezo, J. C.; Barbier, J.; Pinabiaucarlier, M. Influence of Metal-Particle Size and Effect of Gold Addition on the Activity and Selectivity of $\mathrm{Pt} / \mathrm{Al}_{2} \mathrm{O}_{3}$ Catalysts in the Reduction of Nitric-Oxide by Methane. Appl. Catal., A 1993, 97, L11L17.

(2) Denton, P.; Giroir-Fendler, A.; Praliaud, H.; Primet, M. Role of the nature of the support (alumina or silica), of the support porosity, and of the $\mathrm{Pt}$ dispersion in the selective reduction of $\mathrm{NO}$ by $\mathrm{C}_{3} \mathrm{H}_{6}$ under lean-burn conditions. J. Catal. 2000, 189, 410-420.

(3) Lee, J. H.; Kung, H. H. Effect of Pt dispersion on the reduction of NO by propene over alumina-supported Pt catalysts under lean-burn conditions. Catal. Lett. 1998, 51, 1-4.

(4) Xue, E.; Seshan, K.; Ross, J. R. H. Roles of supports, Pt loading and $\mathrm{Pt}$ dispersion in the oxidation of $\mathrm{NO}$ to $\mathrm{NO}_{2}$ and of $\mathrm{SO}_{2}$ to $\mathrm{SO}_{3}$. Appl. Catal., B 1996, 11, 65-79.

(5) Masel, R. I. Principles of Adsorption and Reaction on Solid Surfaces; Wiley: New York, 1996. 
(6) Jayat, F.; Lembacher, C.; Schubert, U.; Martens, J. A. Catalytic $\mathrm{NO}_{x}$ reduction in lean burn exhaust over Pt silica catalysts with controlled Pt particle size. Appl. Catal., B 1999, 21, 221-226.

(7) Olsson, L.; Fridell, E. The influence of Pt oxide formation and $\mathrm{Pt}$ dispersion on the reactions $\mathrm{NO}_{2}<->\mathrm{NO}+1 / 2 \mathrm{O}-2$ over $\mathrm{Pt} / \mathrm{Al}_{2} \mathrm{O}_{3}$ and $\mathrm{Pt} /$ $\mathrm{BaO} / \mathrm{Al}_{2} \mathrm{O}_{3}$. J. Catal. 2002, 210, 340-353.

(8) Hoffmann, J.; Schauermann, S.; Hartmann, J.; Zhdanov, V. P.; Kasemo, B.; Libuda, J.; Freund, H. J. Nanofacet-resolved CO oxidation kinetics on alumina-supported Pd particles. Chem. Phys. Lett. 2002, 354, 403-408.

(9) Zhdanov, V. P.; Kasemo, B. Monte Carlo simulation of the kinetics of rapid reactions on nanometer catalyst particles. Surf. Sci. 1998, 405, 27 37.

(10) Zhdanov, V. P.; Kasemo, B. Simulations of the reaction kinetics on nanometer supported catalyst particles. Surf. Sci. Rep. 2000, 39, 29104.

(11) Zhdanov, V. P. Kinetic oscillations on nm-sized catalyst particles: NO reduction by CO on Pt. Catal. Lett. 2004, 93, 135-138.

(12) Zhdanov, V. P. Electrochemical reactions on catalyst particles with three-phase boundaries. Phys. Rev. E 2003, 67.

(13) Van Santen, R. A.; Neurock, M. Molecular Heterogeneous Catalysis - A conceptual and Computational Approach; Wiley-VCH: Weinheim, 2006.

(14) Ge, Q.; Neurock, M. Structure dependence of NO adsorption and dissociation on platinum surfaces. J. Am. Chem. Soc. 2004, 126, 15511559.

(15) Kieken, L. D.; Neurock, M.; Mei, D. H. Screening by kinetic Monte Carlo simulation of Pt-Au(100) surfaces for the steady-state decomposition of nitric oxide in excess dioxygen. J. Phys. Chem. B 2005, 109, 22342244.

(16) Mei, D. H.; Ge, Q. F.; Neurock, M.; Kieken, L.; Lerou, J. Firstprinciples-based kinetic Monte Carlo simulation of nitric oxide decomposition over Pt and Rh surfaces under lean-burn conditions. Mol. Phys. 2004, 102, 361-369.

(17) Datye, A. K. Electron microscopy of catalysts: Recent achievements and future prospects. J. Catal. 2003, 216, 144-154.

(18) Kresse, G.; Furthmuller, J. Efficient iterative schemes for ab initio total-energy calculations using a plane-wave basis set. Phys. Rev. B $\mathbf{1 9 9 6}$ 54, 11169-11186.

(19) Kresse, G.; Hafner, J. Norm-Conserving and Ultrasoft Pseudopotentials for First-Row and Transition-Elements. J. Phys.-Condes. Matter 1994, 6, 8245-8257.

(20) Perdew, J. P.; Chevary, J. A.; Vosko, S. H.; Jackson, K. A.; Pederson, M. R.; Singh, D. J.; Fiolhais, C. Atoms, Molecules, Solids, and Surfaces - Applications of the Generalized Gradient Approximation for Exchange and Correlation. Phys. Rev. B 1992, 46, 6671-6687.

(21) Mills, G.; Jonsson, H.; Schenter, G. K. Reversible Work TransitionState Theory - Application to Dissociative Adsorption of Hydrogen. Surf. Sci. 1995, 324, 305-337.

(22) Liu, Z. P.; Jenkins, S. J.; King, D. A. Step-enhanced selectivity of NO reduction on platinum-group metals. J. Am. Chem. Soc. 2003, 125, $14660-14661$.

(23) Hopstaken, M. J. P.; Niemantsverdriet, J. W. Lateral interactions in the dissociation kinetics of NO on Rh(100). J. Phys. Chem. B 2000, 104, 3058-3066.

(24) Yeo, Y. Y.; Vattuone, L.; King, D. A. Energetics and kinetics of $\mathrm{CO}$ and $\mathrm{NO}$ adsorption on $\mathrm{Pt}\{100\}$ : Restructuring and lateral interactions. J. Chem. Phys. 1996, 104, 3810-3821.

(25) Getman, R. B.; Schneider, W. F.; Smeltz, A. D.; Delgass, W. N.; Ribeiro, F. H. Oxygen-Coverage Effects on Molecular Dissociations at a Pt Metal Surface. Phys. Rev. Lett. 2009, 102.

(26) Getman, R. B.; Xu, Y.; Schneider, W. F. Thermodynamics of environment-dependent oxygen chemisorption on $\mathrm{Pt}(111)$. J. Phys. Chem. C 2008, 112, 9559-9572.

(27) Halgren, T. A. Merck molecular force field 0.2. MMFF94 van der Waals and electrostatic parameters for intermolecular interactions. J. Comput. Chem. 1996, 17, 520-552.

(28) Hansen, E.; Neurock, M. Predicting lateral surface interactions through density functional theory: application to oxygen on $\mathrm{Rh}(100)$. Surf. Sci. 1999, 441, 410-424.

(29) Hansen, E.; Neurock, M. First-principles based kinetic simulations of acetic acid temperature programmed reaction on $\mathrm{Pd}(111)$. J. Phys. Chem. B 2001, 105, 9218-9229.

(30) Hansen, E. W.; Neurock, M. First-principles-based Monte Carlo simulation of ethylene hydrogenation kinetics on Pd. J. Catal. 2000, 196, 241-252.
(31) Hansen, E. W.; Neurock, M. First-principles-based Monte Carlo methodology applied to O/Rh(100). Surf. Sci. 2000, 464, 91-107.

(32) Mei, D.; Sheth, P. A.; Neurock, M.; Smith, C. M. First-principlesbased kinetic Monte Carlo simulation of the selective hydrogenation of acetylene over Pd(111). J. Catal. 2006, 242, 1-15.

(33) Mei, D. H.; Neurock, M.; Smith, C. M. Hydrogenation of acetyleneethylene mixtures over Pd and Pd-Ag alloys: First-principles-based kinetic Monte Carlo simulations. J. Catal. 2009, 268, 181-195.

(34) Neurock, M.; Mei, D. H. Effects of alloying Pd and Au on the hydrogenation of ethylene: An ab initio-based dynamic Monte Carlo study. Top. Catal. 2002, 20, 5-23.

(35) Neurock, M.; Wasileski, S. A.; Mei, D. From first principles to catalytic performance: tracking molecular transformations. Chem. Eng. Sci. 2004, 59, 4703-4714.

(36) Chin, Y.; Buda, C.; Neurock, M.; Iglesia, E. J. Catal. 2010, submitted.

(37) Garin, F. Mechanism of $\mathrm{NO}_{x}$ decomposition. Appl. Catal., A 2001, 222, 183-219.

(38) Amirnazmi, A.; Boudart, M. Decomposition of Nitric Oxide on Platinum. J. Catal. 1975, 39, 383-394.

(39) Bhatia, D.; McCabe, R. W.; Harold, M. P.; Balakotaiah, V. Experimental and kinetic study of $\mathrm{NO}$ oxidation on model Pt catalysts. $J$. Catal. 2009, 266, 106-119.

(40) Dumesic, J. A.; Rudd, D. F.; Aparicio, L. M.; Rekoske, J. E.; Trevino, A. A. The Microkinetics of Hydrogeneous Catalysis; American Chemical Society (ACS): Washington D.C., 1993; pp 39-42.

(41) Mei, D. H.; Xu, L.; Henkelman, G. Dimer saddle point searches to determine the reactivity of formate on $\mathrm{Cu}(111)$. J. Catal. 2008, 258, 4451.

(42) Mei, D. H.; Xu, L. J.; Henkelman, G. Potential Energy Surface of Methanol Decomposition on $\mathrm{Cu}(110)$. J. Phys. Chem. C 2009, 113, 45224537.

(43) Xu, L. J.; Mei, D. H.; Henkelman, G. Adaptive kinetic Monte Carlo simulation of methanol decomposition on $\mathrm{Cu}(100)$. J. Chem. Phys. 2009, 131.

(44) Mei, D. H.; Hansen, E. W.; Neurock, M. Ethylene hydrogenation over bimetallic $\mathrm{Pd} / \mathrm{Au}(111)$ surfaces: Application of quantum chemical results and dynamic Monte Carlo simulation. J. Phys. Chem. B 2003, 107, $798-810$.

(45) Olsson, L.; Westerberg, B.; Persson, H.; Fridell, E.; Skoglundh, M.; Andersson, B. A kinetic study of oxygen adsorption/desorption and NO oxidation over $\mathrm{Pt} / \mathrm{Al}_{2} \mathrm{O}_{3}$ catalysts. J. Phys. Chem. B 1999, 103, 1043310439.

(46) Bonzel, H. P.; Broden, G.; Pirug, G. Structure Sensitivity of NO Adsorption on a Smooth and Stepped Pt(100) Surface. J. Catal. 1978, 53, 96-105.

(47) Elg, A. P.; Eisert, F.; Rosen, A. The temperature dependence of the initial sticking probability of oxygen on $\mathrm{Pt}(111)$ probed with second harmonic generation. Surf. Sci. 1997, 382, 57-66.

(48) Mulla, S. S.; Chen, N.; Cumaranatunge, L.; Blau, G. E.; Zemlyanov, D. Y.; Delgass, W. N.; Epling, W. S.; Ribeiro, F. H. Reaction of NO and O-2 to $\mathrm{NO}_{2}$ on Pt: Kinetics and catalyst deactivation. J. Catal. 2006, 241, 389-399.

(49) Mulla, S. S.; Chen, N.; Delgass, W. N.; Epling, W. S.; Ribeiro, F. H. $\mathrm{NO}_{2}$ inhibits the catalytic reaction of $\mathrm{NO}$ and O-2 over Pt. Catal. Lett. 2005, 100, 267-270.

(50) Smeltz, A. D.; Getman, R. B.; Schneider, W. F.; Ribeiro, F. H. Coupled theoretical and experimental analysis of surface coverage effects in Pt-catalyzed $\mathrm{NO}$ and $\mathrm{O}-2$ reaction to $\mathrm{NO}_{2}$ on $\mathrm{Pt}(111)$. Catal. Today 2008 , 136, 84-92.

(51) Weiss, B. M.; Iglesia, E. NO Oxidation Catalysis on Pt Clusters: Elementary Steps, Structural Requirements, and Synergistic Effects of $\mathrm{NO}_{2}$ Adsorption Sites. J. Phys. Chem. C 2009, 113, 13331-13340.

(52) Burch, R.; Millington, P. J.; Walker, A. P. Mechanism of the selective reduction of nitrogen monoxide on platinum-based catalysts in the presence of excess oxygen. Appl. Catal., B 1994, 4, 65-94.

(53) Burch, R.; Millington, P. J. Selective reduction of $\mathrm{NO}_{x}$ by hydrocarbons in excess oxygen by alumina- and silica-supported catalysts. Catal. Today 1996, 29, 37-42.

Received for review May 1, 2010 Revised manuscript received August 31, 2010 Accepted September 3, 2010

IE100999E 